\title{
Melanonychia secondary to hydroxyurea
}

\author{
Po-Hua Su • Chorng-Kuang How • \\ David Hung-Tsang Yen $\cdot$ Mu-Shun Huang
}

Received: 6 August 2011/Accepted: 15 October 2011/Published online: 1 November 2011

(C) SIMI 2011

\section{Case report}

A 69-year-old woman with recently diagnosed, essential thrombocytosis was treated with hydroxyurea (1 g daily) and anagrelide ( $0.5 \mathrm{mg}$ twice daily) for 4 weeks. Because of well-controlled platelet count, the use of hydroxyurea was suspended. One month later, she presented to our emergency department (ED) with an extraordinarily high platelet count $\left(2,005,000 \mu \mathrm{L}^{-1}\right)$, and was admitted for emergent plateletpheresis. Physical examination demonstrated the transverse brownish-black pigmentation with different degrees of intensity on 20 nails of hands and feet (Figs. 1, 2). No other mucocutaneous abnormalities were observed.

\section{Discussion}

Melanonychia can be of infections, melanocytic, and exogenous origin, caused by metabolic disorders, or reflect an adverse effect of therapy with specific drugs [1]. Hydroxyurea is a cytostatic agent used to treat myeloproliferative disorders, and long-term treatment is associated with mucocutaneous adverse events and nail hyperpigmentation [2, 3]. Cases of hydroxyurea-induced melanonychia are uncommon [1-3].

P.-H. Su · C.-K. How $(\bowtie) \cdot$ D. H.-T. Yen · M.-S. Huang Emergency Department, Taipei Veterans General Hospital, 201, Sec. 2, Shih-Pai Rd, 112 Taipei, Taiwan e-mail: ckhow@vghtpe.gov.tw

P.-H. Su · C.-K. How · D. H.-T. Yen · M.-S. Huang National Yang-Ming University School of Medicine, Taipei, Taiwan
Hydroxyurea-induced nail pigmentation can occur as early as 8 weeks, and as late as 5 years after the initiation of therapy. It develops predominantly in female patients $[2,3]$. The pathogenesis of hydroxyurea-induced melanonychia is not clear. Longitudinal bands appear to be the most common pattern. Transverse melanonychia seems to occur in relation to the intermittent courses of chemotherapy because of a direct toxic effect on the nail matrix [3]. The thumb and index fingernails appear to be the sites most frequently affected, but any of the fingernails and toenails may be compromised [3].

It would be helpful to distinguish these from the transverse white bands on the nail plate, known as Mees' lines, seen with heavy metal poisoning, such as arsenic and thallium. Other previously reported causes of Mees' lines included severe infection, renal disease, cardiac failure, malignant disease, and chemotherapy [4].

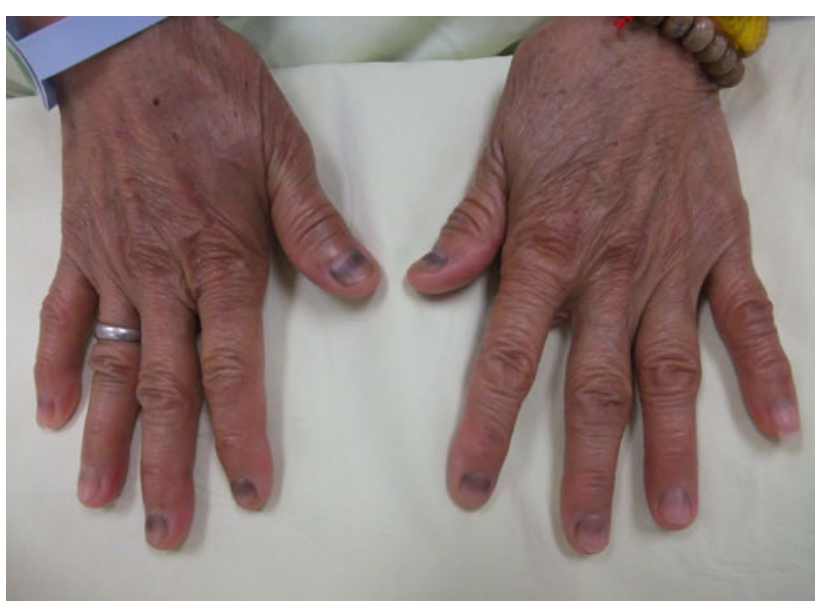

Fig. 1 Transverse hyperpigmentation of the nails on hands 


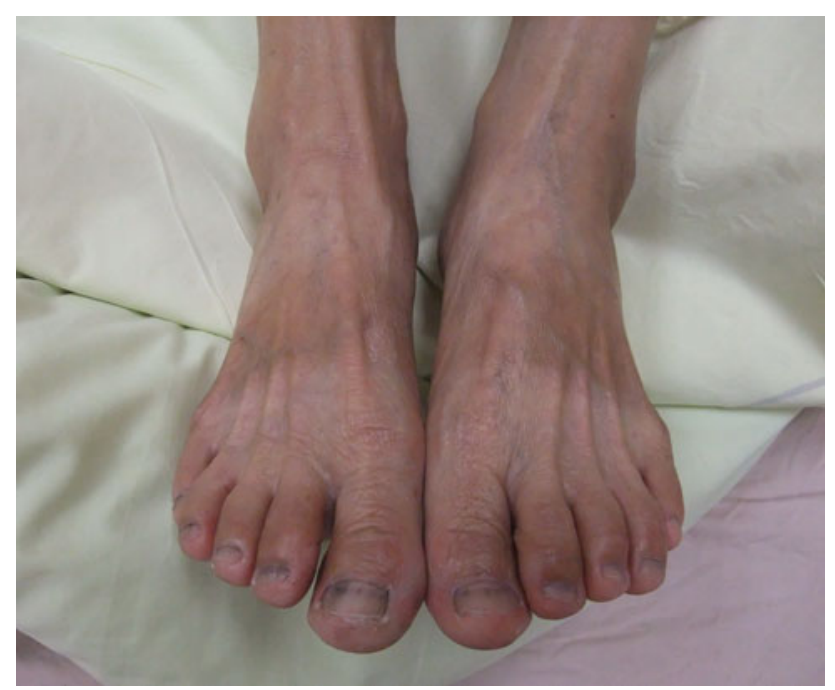

\section{References}

1. Ceulen RPM, Frank J, Poblete-Gutierrez P (2007) Nail hyperpigmentation due to hydroxycarbamide. Int J Dermato 146(Suppl 3): $13-15$

2. Hernandez-Martin A, Ros-Forteza S, de Unamuno P (1999) Longitudinal, transverse, and diffuse nail hyperpigmentation induced by hydroxyurea. J Am Acad Dermatol 40:333-334

3. Aste N, Fumo G, Contu F, Aste N, Biggio P (2002) Nail pigmentation causes by hydroxyurea: report of 9 cases. J Am Acad Dermatol 47:146-147

4. Chauhan S, D'Cruz S, Singh R, Sachdev A (2008) Mees' lines. Lancet 372:1410

Fig. 2 Transverse hyperpigmentation of the nails on feet

\section{Conflict of interest None.}

